\title{
PERFORMANCE OF UNREINFORCED MASONRY STRENGTHENED WITH BED JOINT REINFORCED REPOINTING
}

\author{
LUCIA LICCIARDELLO ${ }^{1}$, JAN G. ROTS ${ }^{2}$, RITA ESPOSITO $^{2 *}$ \\ ${ }^{1}$ Researcher; Department of Materials, Mechanics, Management and Design, Delft University of \\ Technology, Stevinweg 1, 2628CN Delft, The Netherlands; 1.licciardello@tudelft.nl. \\ ${ }^{2}$ Full Professor; Department of Materials, Mechanics, Management and Design, Delft University of \\ Technology, Stevinweg 1, 2628CN Delft, The Netherlands; j.g.rots@tudelft.nl. \\ ${ }^{2}$ Assistant Professor; Department of Materials, Mechanics, Management and Design, Delft University \\ of Technology, Stevinweg 1,2628CN Delft, The Netherlands; r.esposito@tudelft.nl.
}

Keywords: unreinforced masonry (URM), settlement, induced seismicity, bed joint reinforcement, twisted steel bars, in-plane test.

\begin{abstract}
Bed joint reinforced repointing is a strengthening method often used in the Netherlands to counteract settlement damage. This strengthening technique consists of cutting a slot in the mortar joint and installing twisted steel bars embedded in a high-strength repair mortar. Due to the increase in seismic activities, triggered by gas extraction in the region of Groningen (northern part of the Netherlands), it is of interest to investigate whether this strengthening technique is efficient against seismic load.

In order to characterize the performance of the bed joint reinforced repointing using twisted steel bars, an experimental campaign was conducted at Delft University of Technology. A quasi-static cyclic in-plane test on a full-scale wall was performed; similar tests on unstrengthened specimens were available from a previous experimental campaign [1][2] and were used for comparison. Moreover, small scale pull-out tests were performed to study the interaction between the steel bars and the repair mortar.

By comparing the response of unstrengthened and strengthened masonry specimens, it is observed that the use of bed joint reinforced repointing can provide an increase in terms of ductility and displacement capacity, but not in terms of force capacity. Regarding the serviceability limit state, a reduction in crack width and an increase of load at onset of cracking were observed. The preliminary information obtained for the presented case study provides the ground for futher research as well as benchmark for numerical modelling.
\end{abstract}

\section{$1 \quad$ INTRODUCTION}

The bed joint reinforced repointing technique consists in the insertion of reinforcement (steel, stainless steel or FRP bars) in shovelled mortar bed joints rifilled with repair mortar. This technique does not influence the aesthetic aspect of the building and it can be applied with limited invasiveness; for this reason it is often used to preserve the historical and the artistic aspects of cultural heritage buildings. In the Netherlands, where the buildings' stock is mainly composed of unreinforced masonry, this techniques has been largely applied to counteract settlement damage. During the last years, the phenomena of induced seismicity, due to the gas extraction, considerably increased in the region of Groningen (northern part of the Netherlands), causing damage to the unreinforced masonry buildings. Therefore, it is of 
interest to investigate the performance of masonry strengthened with bed joint reinforcement under seismic loading.

Previous studies on reinforced repointing mainly focused on evaluating its effictivness against settlement and creep damage, while less attention has been paid to the seismic performance of masonry strengthened with bed joint reinforcement. Previous researchers [3][4], showed no significant improvement of the strength of masonry, but thanks to the confining action provided by the bed joint reinforcement a reduction of the dilation and a reduced cracks pattern were obtained. In literature, limited information on the seismic performance of masonry strengthened with bed joint reinforcement is available. In this respect, researchers mainly performed diagonal-shear compression tests on wallets. Ismail et al. [5] made a comparison of the bed joint reinforcement with a near-surface mounted technique made by placing steel bars in the vertical direction, being this often done to prevent out-of-plane failure of unreinforced masonry buildings in countries prone to strong intensity seismic events.

To this purpose an experimental campaign was conducted at Delft University of Technology; a quasi-static cyclic in-plane test on a full-scale wall was performed. Within this testing campaign also the performance against settlement damage was investigated by performing four-point bending tests on strengthened and unstrengthened masonry wallettes [6]; however in this paper only the results obtained from the cyclic in-plane test are presented and discussed. The experimental results obtained from the test on the strengthened wall are compared with the results obtained on similar unstrengthened walls obtained from previous experimental campaign the type of specimen, results that were obtain results are discussed in suts

2 MATERIALS AND METHODS

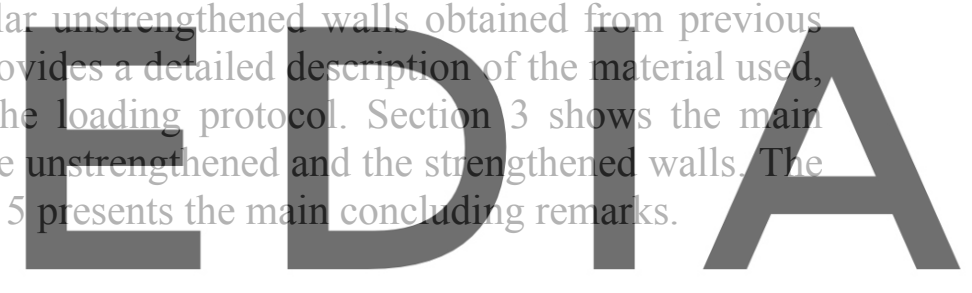

Register for free at https//www.scipedia.com to download the version without the watermark

To assess the performance of the bed joint reinforcement with twisted steel bars against seismic load, a quasi-static cyclic in-plane test on a full-scale strengthened wall was performed and compared with available data on unstrengthened walls tested in previous studies [1][2]. Two different walls were considered: a pre-damaged wall TUD-COMP-45 [2] and an undamaged and unstrengthened wall TUD_COMP-41 [1]. The geometry of the wall was the same and was defined based on typical dimensions presents in Dutch detached house [7] (Figure 1a). The walls were made of solid clay single-wythe masonry and built in running bond, Table 1 lists the material properties of the single components and of masonry. Both walls were tested under a cyclic loading protocol [1][2] up to a light damage state in which a maximum crack width around $2 \mathrm{~mm}$ was obtained (light blue lines Figure 1a). To reproduce the damage caused by settlement before an earthquake, in the wall TUD_COMP-45 [2] a pre damage was simulated by creating un-bonded brick-joint interfaces using thin plastic strips (orange lines in Figure 1a). Afterwards, only wall TUD_COMP-45 was strengthened (Figure 1a) and re-tested up to light damage state. Eventually, both walls were tested up to nearcollapse state. To evaluate the performance of the strengthening measures for the serviecibility limit state, the comparison is made by considering the results obtained for the 
light damage state on wall TUD_COMP-45 before and after the strengthening measure was applied, while the considerations for near collapse limit state are drawn from the comparison between the two walls.

The layout of the bed joint reinforcement mainly reflected the application in practice. The areas above and below the window opening are the most prone to vertical damage due to settlement. Consequently, to counteract the settlement damage two twisted steel bars were installed in the mortar joints in the area above and below the window opening every three mortar courses (green lines in Figure 1a); additionally one bar every five/six mortar courses (pink line in Figure 1a) was installed in the piers (vertical masonry portion next to the window opening) and diagonal ties (blue lines in Figure 1a) were installed in correspondence of the existing diagonal cracks at the corners of the window opening. Figure $1 \mathrm{~b}$ shows the detail of a strengthened section and Table 2 lists the properties of the cement-based repair mortar, twisted steel bars and diagonal ties used for the strengthening.
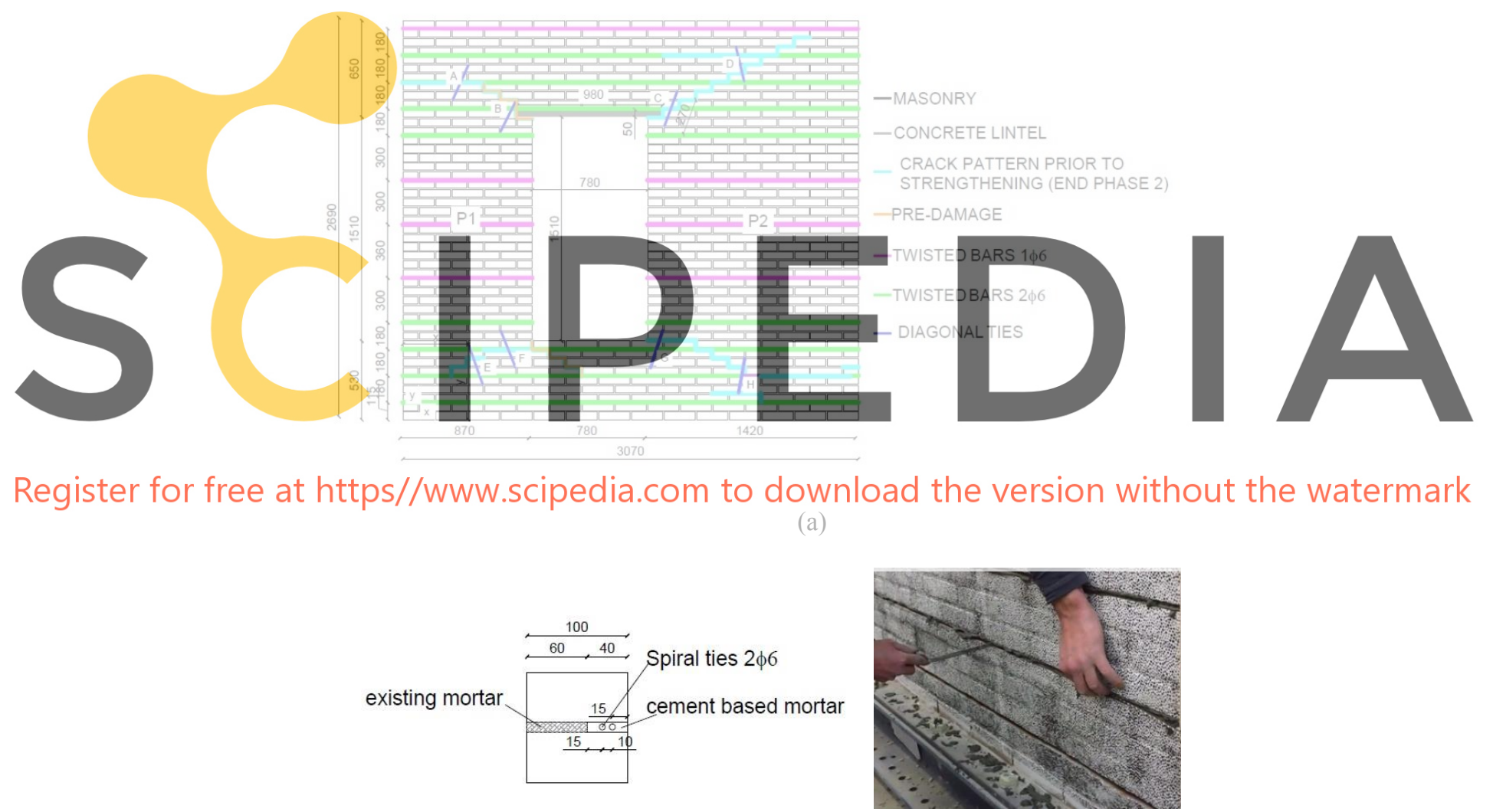

(b)

Figure 1: Overview of the adopted specimen and its features: (a) dimensions and strengthening configuration; (b) detail of the strengthened bed joint and execution of the intervention. 
Table 1: Material properties of replicated clay brick masonry built in July 2018 [2].

\begin{tabular}{|c|c|c|c|c|c|c|}
\hline Material properties & Symbol & Unit & Average & C.o.V & $\begin{array}{l}\text { No. } \\
\text { tests }\end{array}$ & Standard \\
\hline $\begin{array}{l}\text { Normalised compressive strength of masonry unit } \\
\qquad(210 \times 100 \times 50-\mathrm{mm})\end{array}$ & $f_{b}$ & $\mathrm{MPa}$ & 28.31 & 0.10 & 9 & $\begin{array}{l}\text { EN 772- } \\
1: 2000[8]\end{array}$ \\
\hline Flexural strength of masonry unit & $f_{b t}$ & $\mathrm{MPa}$ & 6.31 & 0.11 & 8 & $\begin{array}{c}\text { EN } \\
6790: 2015 \text { [9] }\end{array}$ \\
\hline $\begin{array}{l}\text { Compressive strength of construction mortar } \\
\text { (cement:lime:sand ratio of } 1: 2: 9)\end{array}$ & $f_{m}$ & $\mathrm{MPa}$ & 3.59 & 0.09 & 24 & \multirow[t]{2}{*}{$\begin{array}{l}\text { EN 1015- } \\
11: 1999[10]\end{array}$} \\
\hline Flexural strength of construction mortar & $f_{m t}$ & $\mathrm{MPa}$ & 1.55 & 0.10 & 12 & \\
\hline Density of masonry & $\rho$ & $\mathrm{kg} / \mathrm{m}^{3}$ & 1628 & 0.01 & - & - \\
\hline $\begin{array}{l}\text { Compressive strength of masonry in the direction } \\
\text { perpendicular to bed joints }\end{array}$ & $f_{m}^{\prime}$ & $\mathrm{MPa}$ & 12.93 & 0.07 & \multirow[b]{2}{*}{3} & \multirow[b]{2}{*}{$\begin{array}{l}\text { EN 1052- } \\
1: 1998[11]\end{array}$} \\
\hline $\begin{array}{l}\text { Elastic modulus of masonry in the direction } \\
\text { perpendicular to bed joints calculated between } 1 / 3 \\
\text { and } 1 / 10 \text { of the maximum stress }\end{array}$ & $E_{3}$ & $\mathrm{MPa}$ & 3190 & 0.24 & & \\
\hline Flexural bond strength & $f_{w}$ & $\mathrm{MPa}$ & 0.08 & 0.32 & 10 & $\begin{array}{l}\text { EN 1052- } \\
5: 2002[12]\end{array}$ \\
\hline Masonry initial shear strength & $f_{v 0}$ & $\mathrm{MPa}$ & 0.13 & - & \multirow{2}{*}{6} & EN 1052- \\
\hline Masonry shear friction coefficient & $\mu$ & - & 0.82 & - & & $3: 2002[13]$ \\
\hline
\end{tabular}
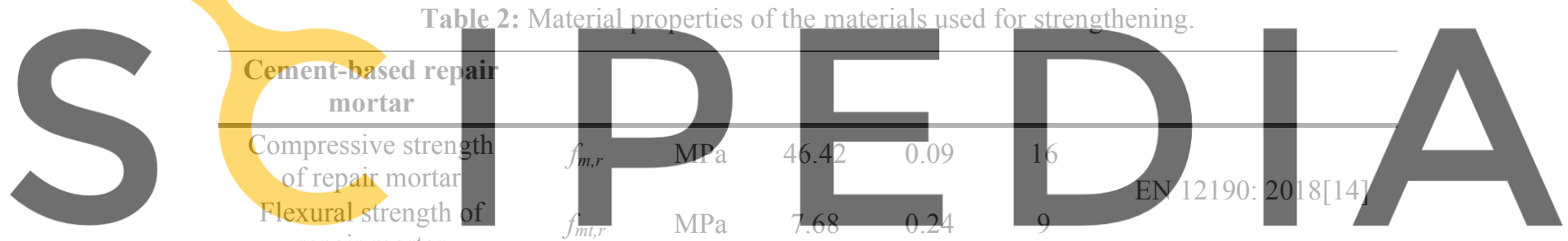

repair mortar

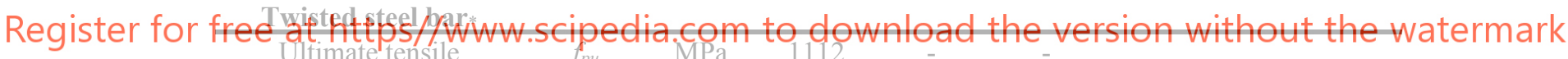

\begin{tabular}{cccccc} 
Ultimate tensile & $F_{m u}$ & $\mathrm{MPa}$ & 1112 & - & - \\
Tensile strength & $F_{p u}$ & $\mathrm{kN}$ & 10 & - & - \\
$0.2 \%$ Proof stress & $f_{p y}$ & $\mathrm{MPa}$ & 900 & - & - \\
\hline Diagonal tie $*$ & & & & & \\
\hline Ultimate tensile & $f_{m u}$ & $\mathrm{MPa}$ & 1398 & - & - \\
Tensile strength & $F_{p u}$ & $\mathrm{kN}$ & 13 & - & - \\
$0.2 \%$ Proof stress & $f_{p y}$ & $\mathrm{MPa}$ & 1100 & - & - \\
\hline *Data provided by producer & & &
\end{tabular}

The effectiveness of the bed joint reinforcement depends on the bond behaviour between the mortar and the twisted steel bar, which can be studied with pull-out test [15]. Within this study, the bond behaviour between the twisted steel bars and the repair mortar and between the diagonal ties and the masonry is considered. In the first case, the standar EN 1766 [16] was adopted by embedding the repair mortar and the twisted steel bars in concrete cubes with dimensions 400x400x250-mm. In the second case, diagonal ties were vertically installed in a masonry triplet with dimensions $210 \times 170 \times 100-\mathrm{mm}$. The set-up used for the two types of test was the same and similar to the one adopted in a previous testing campaign [17]. For the two types of test a monotonic load was applied; in addition for the diagonal ties cyclic pull-out 
tests were also performed [17]. Figure 2 shows the experimental results in terms of bondstrenght versus relative displacement curve. For the cyclic tests, the envelope curve was calculated considering the force and the displacement in correspondence of the peak force and in correspondence of a drop of $20 \%$ of the maximum force [17]. These curves can serve as input for numerical analyses.

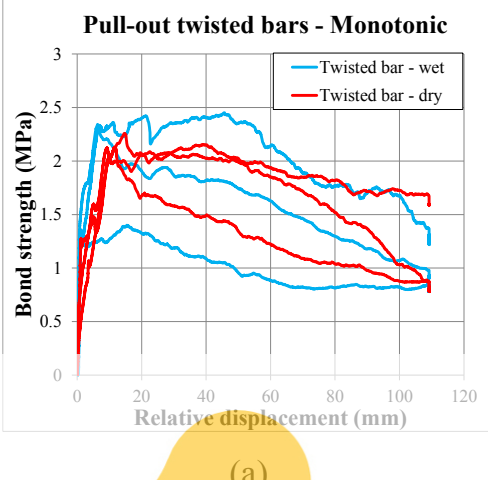

(a)

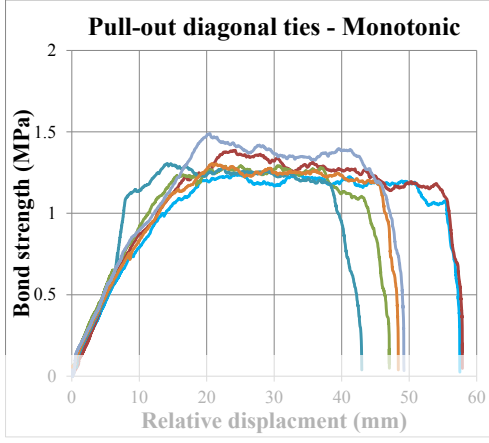

(b)

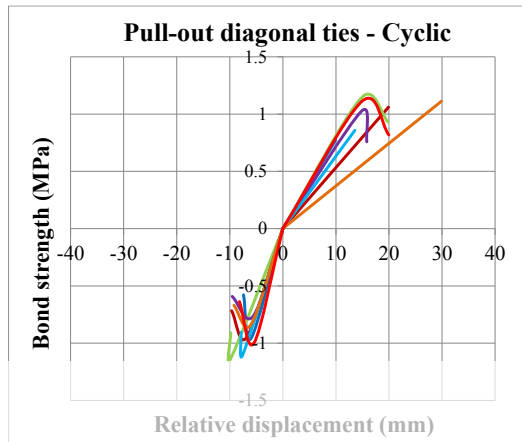

(c)

Figure 2: Bond-strength versus relative displacement curve: (a) monotonic test on twisted steel bars; (b) monotonic test on diagonal ties; (c) cyclic test on diagonal ties.

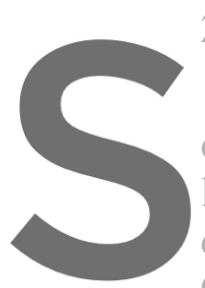

\subsection{Test set-up andlloading scheme}

\section{Figure 3 shows the set-up} overburden of $0.12 \mathrm{MP}$

load was applied with a direction is defined whe

On the front
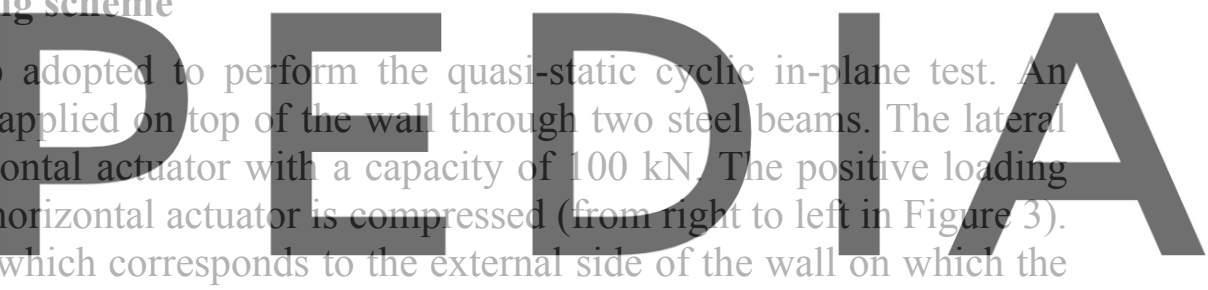

bed joint reinforcement was installed, Digital Image Correlation (DIC) was applied to detect

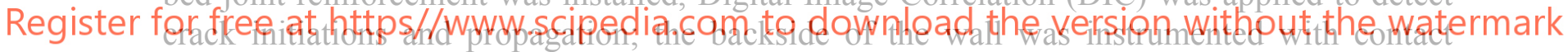
sensors.

The walls were tested under a quasi-static cyclic lateral in-plane load in a cantilever configuration by controlling the horizontal displacement of the jack and the net horizontal displacement was calculated as the displacement of the top beam with respect to the external reference excluding possible rotations of the set-up and possible horizontal displacement of the bottom beam with respect to the external reference. In Figure 4 the net horizontal displacement is shown and it is similar for the unstrengthened and strengthened configuration. The lateral load was applied in three phases: phase 1 and phase 2 up to light damage state with the same loading protocol as used in Ref. [2]; phase 3 up to near collapse state with the loading protocol derived from a previous study and representative of a Groningen type earthquake [18]. In phase 1 and 2 each cycle was composed of 30 runs, in phase 3 the first two cycles were composed on 2 runs and the remaning were composed of a single run (Figure 4). A cycle is defined as the time interval in which the same target horizontal displacement was applied with the same rate. A run is defined as the time needed to impose the target displacement in the positive and negative loading direction up to returning to the original position of the wall. During the light damage phase, the lateral load was applied with a 
constant rate equal to $0.125 \mathrm{~mm} / \mathrm{s}$; during the near-collapse phase, the load-rate varied between 0.03 to $1 \mathrm{~mm} / \mathrm{s}$ so that each cycle lasted $5 \mathrm{~min}$ (except for the last cycle that lasted 4 min because the test was stopped as it is explained in section 3 ).
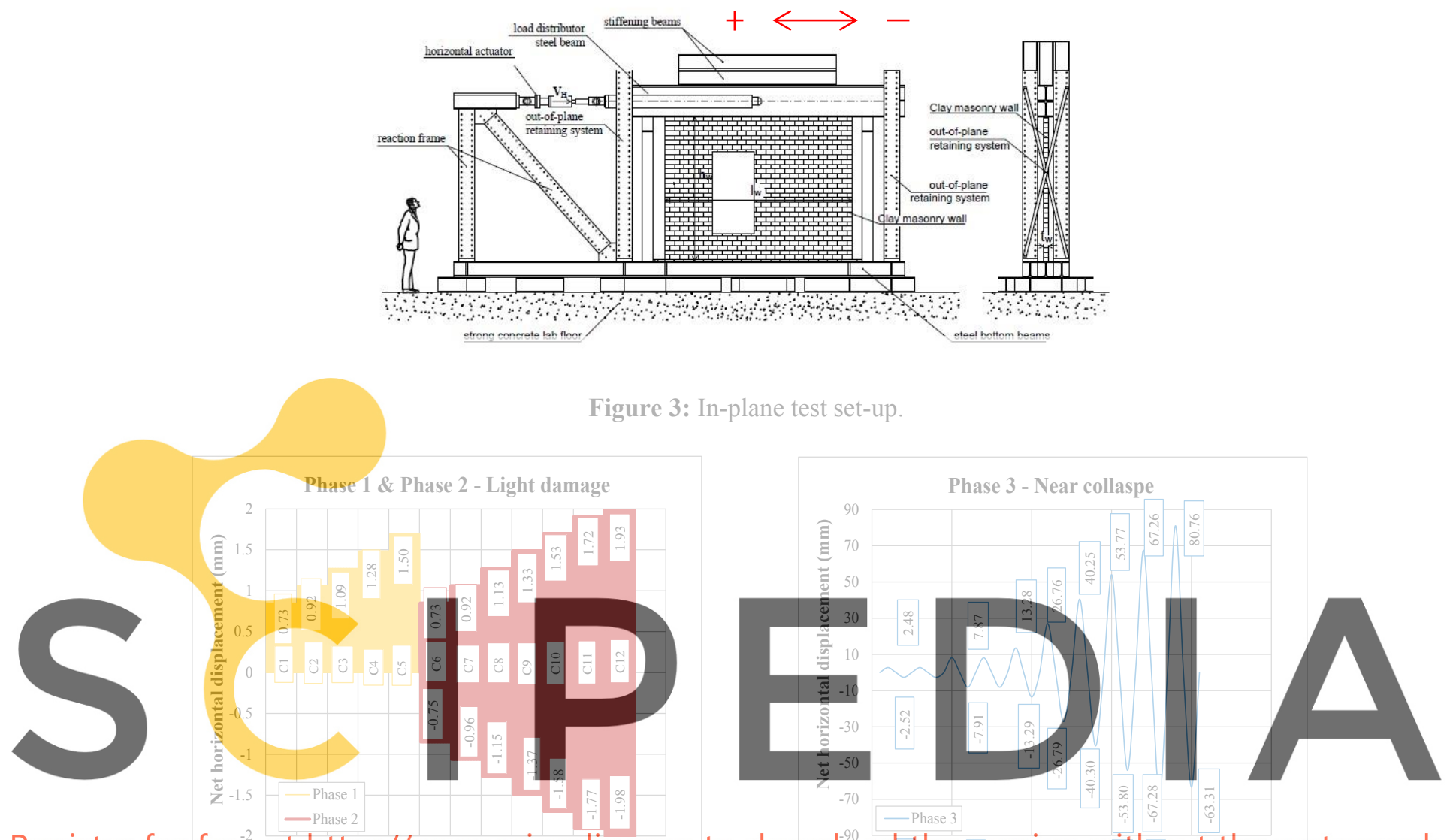

Register for freẻ at https//www.scipedia.com to download the version without the watermark

(a)

(b)

Figure 4: Loading scheme: (a) light damage phases 1 and 2; (b) near collapse phase 3.

In this section, the results obtained from the in-plane test on the unstrengthened and strengthened walls are presented in terms of crack pattern and base shear force versus net horizontal displacement (Figure 5).

Considering the unstrentghened case, the response is analysed for specimen TUD_COMP45 [2] up to light damage state and for specimen TUD_COMP-41 [1][2] up to the near collapse state. The initial stiffness, calculated in the first cycle of phase $1(\mathrm{C} 1 \mathrm{~d}=0.72 \mathrm{~mm})$ was equal to 29.06 and $26.88 \mathrm{kN} / \mathrm{mm}$ for wall TUD_COMP-45 [2] and TUD_COMP-41[1], respectively. A similar response was observed up to the maximum base shear force. The maximum base shear force was equal to $20.72 \mathrm{kN}(\mathrm{C} 15 \mathrm{~d}=11.11 \mathrm{~mm})$ and to $-19.54 \mathrm{kN}(\mathrm{C} 14$ $\mathrm{d}=-7.97 \mathrm{~mm}$ ) for the positive and negative loading direction, respectively. For wall 
TUD_COMP-41, the ultimate displacement was equal to approximately $40 \mathrm{~mm}$ in both loading directions, corresponding to a ultimate drift of 1.61/-1.49\%. Both walls show the formation of diagonal stepwise cracks from the window corners. To highlight the small differences in crack position, for wall TUD_COMP-41 the subscript "a" is added to the crack number. Crack 1 and 2 developed during phase 1 (orange color in Figure 5a) with a stepwise configuration starting from the bottom right and the top left corner of the window opening, respectively. The onset of cracking was in correspondence of cycle $\mathrm{C} 1(\mathrm{~d}=0.72 \mathrm{~mm})$ at a load equal to $19.6 \mathrm{kN}$. During phase 2 (red color in Figure 5a), crack 3 and 4 evolved with a stepwise configuration from the bottom left and top right corner of the window opening, respectively. During Phase 3 (blue color in Figure 5e), existing cracks mainly evolved by increasing their length and width.

Considering the strengthened case, the response is analysed considering the wall TUD_COMP-45 both for the light damage and the near collapse state. The initial stiffness, calculated in the first cycle of Phase $1(\mathrm{C} 1 \mathrm{~d}=0.73 \mathrm{~mm})$, was equal to $28.78 \mathrm{kN} / \mathrm{mm}$. The maximum base shear force was equal to $25.14 \mathrm{kN}(\mathrm{C} 16 \mathrm{~d}=23.08 \mathrm{~mm})$ and to $-23.46 \mathrm{kN}(\mathrm{C} 14$ $\mathrm{d}=-7.90 \mathrm{~mm}$ ) for the positive and negative loading direction, respectively. At the end of the near collapse phase, the ultimate displacement was equal approximately to $80 \mathrm{~mm}$ and to 60 $\mathrm{mm}$ for the positive and negatve loading direction, corresponding to an ultimate drift of 2.99/$2.34 \%$. The test was stopped because out-of-plane deformation occurred in both piers (vertical masonry portion next to the window opening). Crack 1 developed during Phase 1 (orange color in Figure 5c), with a stepwise configuration from the bottom right corner of the window opening; crack $2 *$ developed horizontally at the top left corner of the window opening in a mortar joint where the reinforcement was not present (a subscript is used to mark the crack because it had a different shape/location with respect to the unstrengthened wall a will be explained in Section 4). The onset of cracking was in correspondence of cycle C/ ( d $0.73 \mathrm{~mm}$ ) at a load ecual to $19.7 \mathrm{kN}$. Crack 3 and 4 dereloped during phase 2 (red color in
Figure $5 \mathrm{c}$ ) with a stepwise configuration at the bottom left corner and at the top right corner

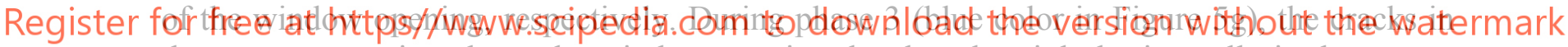
the masonry portion above the window opening developed mainly horizontally in the mortar joints where the reinforcement was not present, while in the portion below the window opening the cracks propagated in the mortar joints forming an arch mechanisms triggered by the bars. Approaching the end of the test, thanks to the progression of damage at cycle C18 (d $=53.77 /-53.80 \mathrm{~mm})$ the cracks started also in the bricks at the bottom left corner and at cycle $19(\mathrm{~d}=67.26 /-67.28 \mathrm{~mm})$ at the bottom right corner of the window opening. 


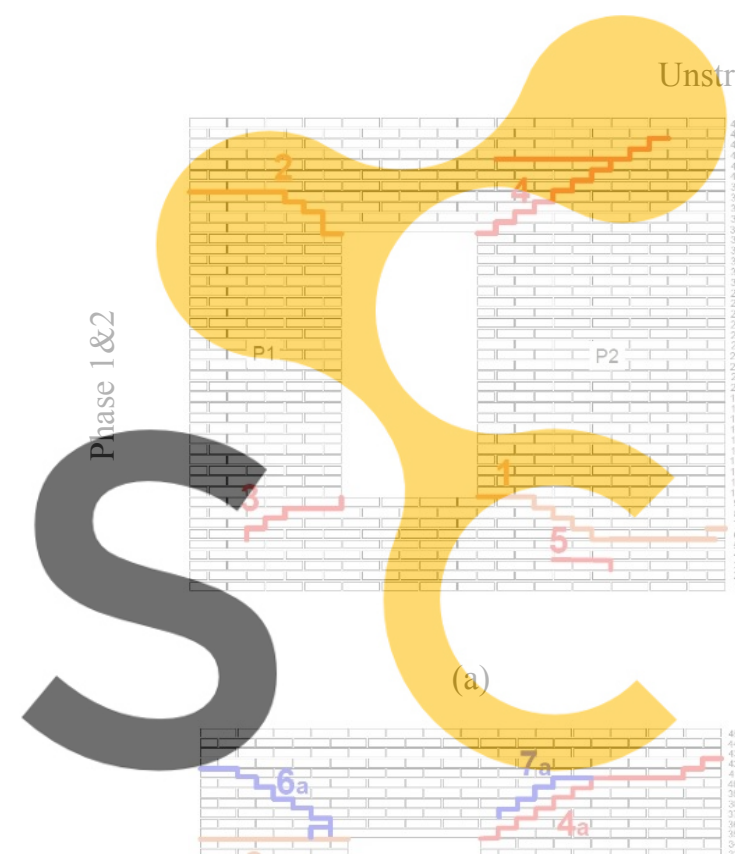

Unstrengthened wall

Strengthened wall
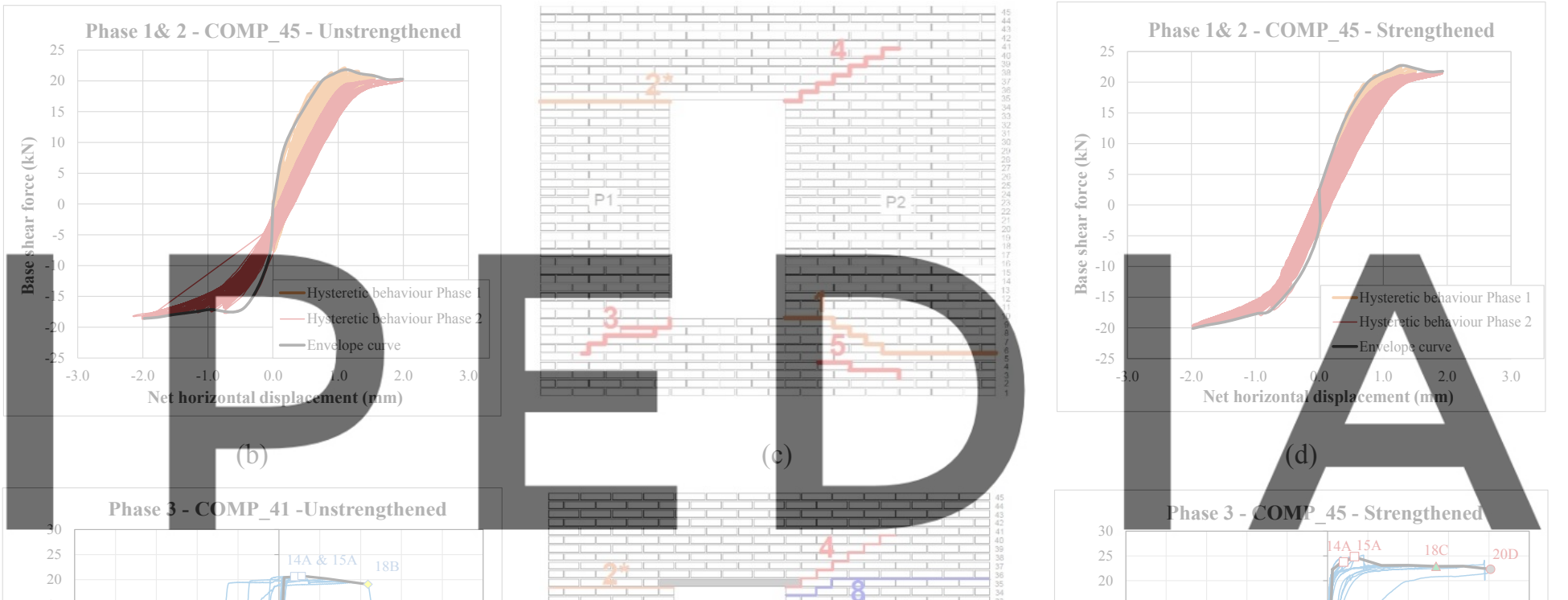

Register for free at https//w wiv.s.

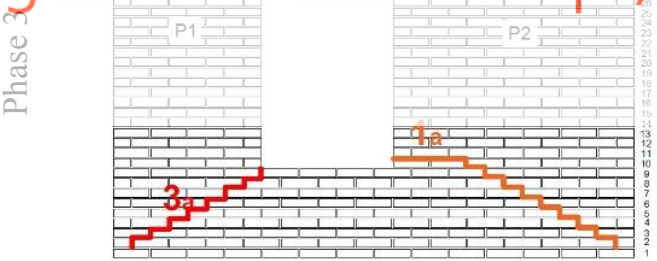

(e)

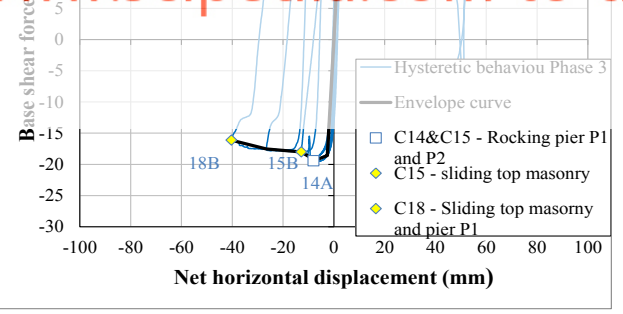

(f)

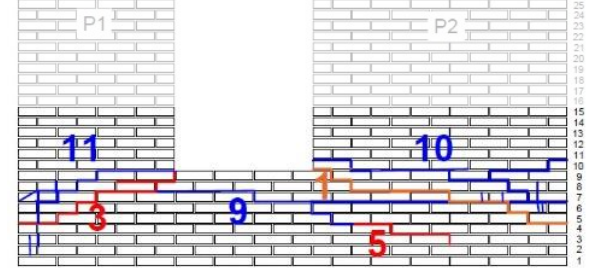

(g)

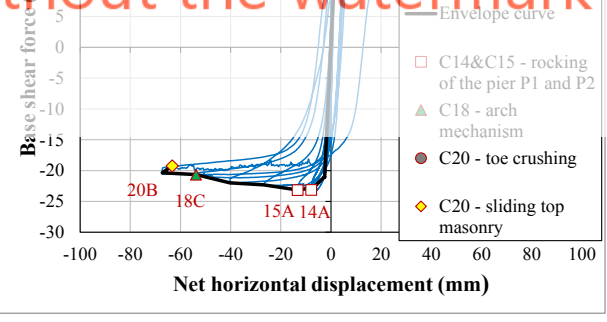

(h)

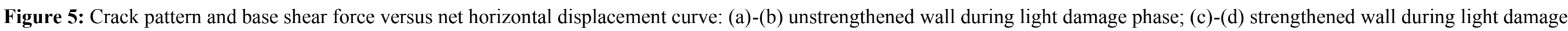
phase; (e)-(f) unstrengthened wall during near collapse phase; $(\mathrm{g})$-(h) strengthened wall during near collapse phase 


\section{DISCUSSION OF THE RESULTS}

In this section, the comparison between the unstrengthened and the strengthened wall is carried out in terms of crack width and length for the light damage phase, and in terms of failure mechanisms and equivalent bilinear curve [19] for the near collapse phase

Figure 6 shows the comparison in terms of crack width and length for the four main stepwise cracks formed at the window corners at the end of phase $1(\mathrm{~d}=1.50 \mathrm{~mm})$ and at the end of phase $2(\mathrm{~d}=1.93 /-1.98 \mathrm{~mm})$. A reduction in crack width between -20 and $25 \%$ and in crack length between -25 and $56 \%$ was observed. Due to the different shape of Crack $2 *$ for the strengthened wall, horizontal crack rather than stepwise crack, this is not included in the comparison. A delay at the onset of cracking was also observed: during phase 1 crack 2 started at cycle $\mathrm{C} 2(\mathrm{~d}=0.91 \mathrm{~mm})$ and at cycle $\mathrm{C} 4(\mathrm{~d}=1.28 \mathrm{~mm})$ for the unstrengthened and strengthened wall, respectively; during phase 2 crack 3 started at cycle $C 7$ ( $d=0.94 /-0.96$ $\mathrm{mm})$ and at cycle $\mathrm{C} 8(\mathrm{~d}=1.13 /-1.15 \mathrm{~mm})$ for the unstrengthened and strengthened configuration, respectively. For the near collapse phase a quantitative comparison in terms of crack width and length cannot be performed since the accuracy of the DIC for crack width larger then $2 \mathrm{~mm}$ is significantly reduced. In correspondence of cycle C18 ( $\mathrm{d}=53.77 /-53.80$ $\mathrm{mm}$ ), which corresponds to the end of the test for the unstrengthened configuration, it can be observed qualitatively that the crack width was smaller in the strengthened wall.

Figure 7 shows the failure mechanisms of the masonry components during the near collapse phase (phase 3) for both unstrengthened and strengthened wall. Relevant load levels, corresponding to the occurrence of fal ure mechanisms, are identified and indicated with
markers in Figure 5. Four main failure mechanisms are considered: rocking of one of the piers
(marker A), sliding between two part of the wall (marker B), arch nechanism below the
window opening (marker C) and toe crushing (marker D). Considering the unstrengthened
wall, until cycle C14 (d = $7.89 /-7.97 \mathrm{~mm}$ ) the rocking of the piers was the prevailing mechanisms in both loading directions (point 14-A). At cycle C15 ( $\mathrm{d}=-12.82 \mathrm{~mm})$, sliding of

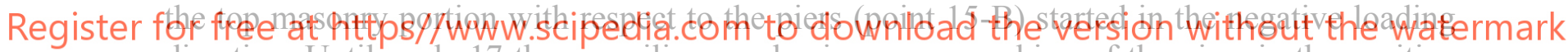
direction. Until cycle 17 the prevailing mechanisms were rocking of the piers in the positive loading direction and sliding of the top masonry portion with respect to the piers for the negative loading direction. At cycle $18(\mathrm{~d}=43.63 \mathrm{~mm})$ also sliding of the top masonry portion and of the pier P2 occurred with respect to the pier P1 and the bottom masonry portion in the positive loading direction (point 18-B). Considering the strengthened wall, until cycle $\mathrm{C} 17$ rocking of the piers was the prevailing mechanism in both loading directions (points 14-A and 15-A). At cycle C18 $(\mathrm{d}=53.77 /-53.80 \mathrm{~mm})$ an arch mechanism formed in the area below the window opening thanks to the presence of the bars (point 18-C). At cycle $20(\mathrm{~d}=80.96 /-63.31 \mathrm{~mm})$ toe crushing (Figure 8a) of the bottom right corner (point 20-D) and sliding of the top masonry portion with respect to the piers (point 20-B) occurred for the positive and negative loading direction, respectively. The test on the strengthened wall was stopped due to excessive out-of-plane deformation of the piers (Figure 8b) .

Figure 9a shows the out-of-plane deformation versus the net horizontal displacement for the unstrengthened (blue triangles) and strengthened wall (red circles). For the unstrengthened wall a maximum out-of-plane deformation of $10 \mathrm{~mm}$ was observed in the last cycle C18. For the strengthened wall a similar magnitude of out-of-plane deformation is observed at cycle $\mathrm{C} 15(\mathrm{~d}=13.28 /-13.29 \mathrm{~mm})$ especially for the narrow pier P1. In the last cycle $(C 20, d=-63$ $\mathrm{mm}$ ) both piers experience a significant out-of-plane deformation of approximately $40 \mathrm{~mm}$ for 
the negative loading direction. The cause of this excessive out-of-plane deformation can be ascribed to the asymmetric position of the twisted steel bars in the thickness of the wall, which becomes of relevance for extensive in plane damage

To compare the seismic performance of the strengthened and unstrengthened wall, the equivalent bilinear curve was adopted [19] (Figure 9b). The strengthened wall showed a slight increment $(+15 \%)$ in terms of base shear force, but a substantial increment in terms of displacement capacity $(+40-45 \%)$ and ductility $(+30-40 \%)$ was observed. The ultimate drift increased from 1.61 to $2.99 \%$ and from -1.49 to $-2.34 \%$ in the positive and negative loading direction, respectively.

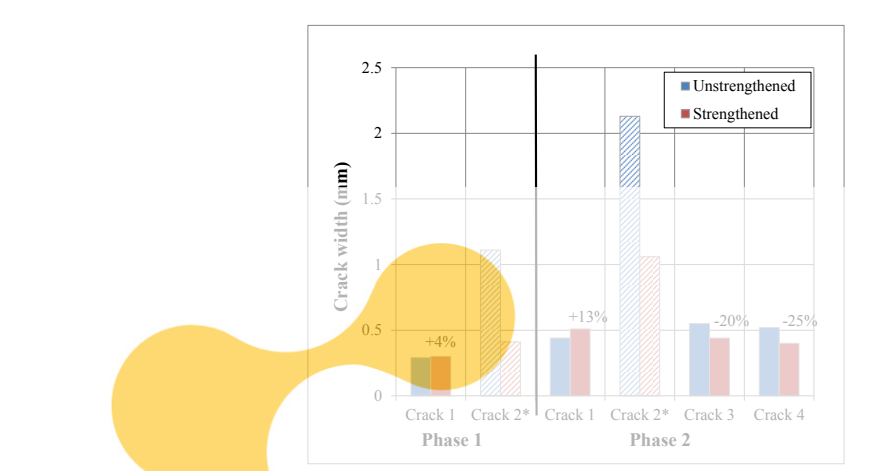

(a)

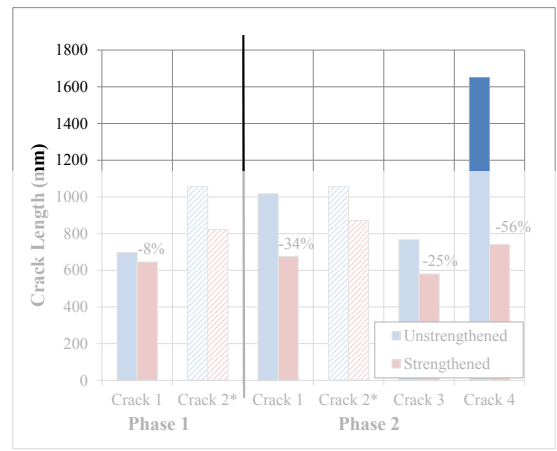

(b)

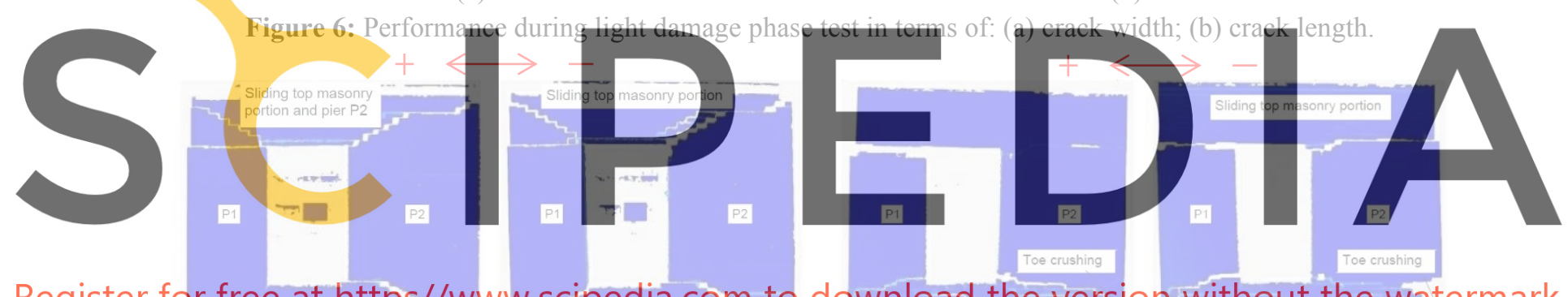

Register for free at https//www.scipedia.com to download the version without the watermark

(a)

(b)

(c)

(d)

Figure 7: Relevant failure mechanism observed through DIC analysis at the end of the near collapse phase (phase 3): (a)-(b) unstrengthened wall; (c)-(d) strengthened.

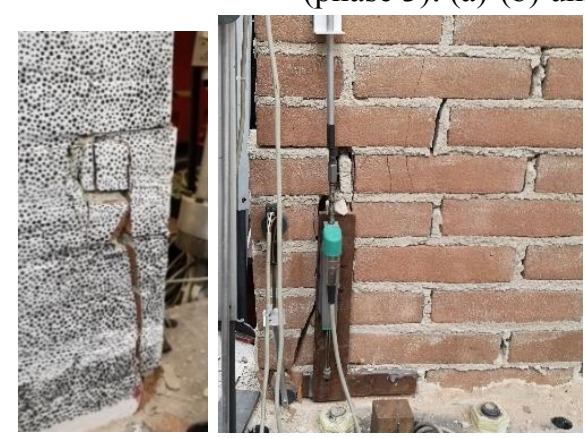

(a)

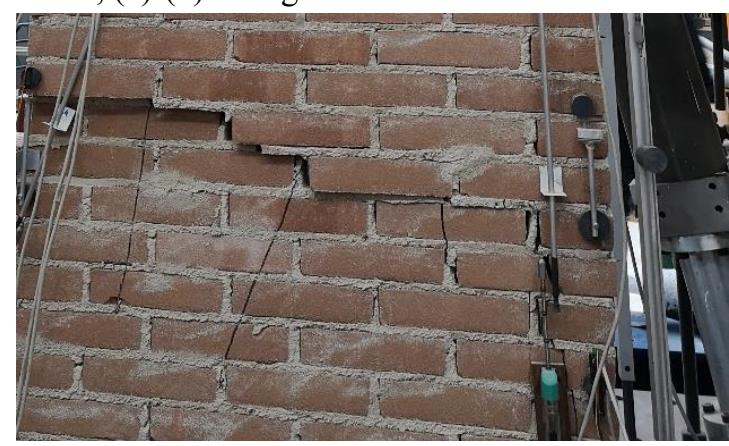

(b)

Figure 8: Detail of some mechanisms: (a) toe crushing and cracks in the brick at bottom right corner; (b) out-of plane of the pier P1 and cracks in the brick at bottom left corner. 


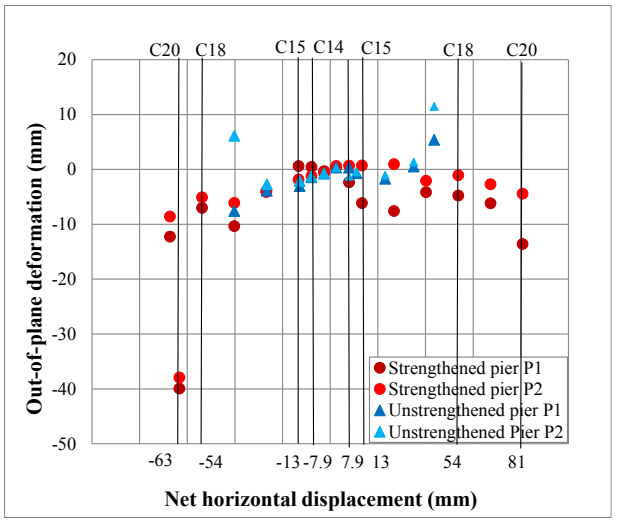

(a)

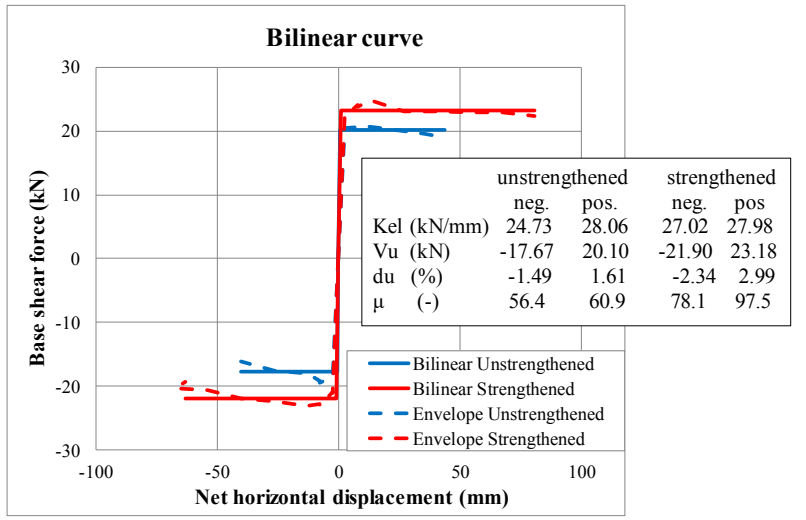

(b)

Figure 9: (a) Out-of-plane deformation; (b) bilinear curve.

\section{CONCLUDING REMARKS}

The bed joint reinforcement is often used in the Netherlands against settlement damage in historical unreinforced masonry buildings, because it does not influence the aesthetic aspect of the buildings. In addition in the last years, the induced seismic events are increasing in the region of Groningen and it is of interest to investigate whether this strengthening method is efficient against seismic load.

To this purpose, a quasi-static in-plane test on a full-scale wall was performed at Delft University of Technology. The selected wall was representative of residential rather than historical buildings since it was single wythe, the adopted mortar was cement and lime-based and the pre-compression load applied was very low; while in historical buildings the walls are generally double wythe and the adopted mortar is generally lime-based. However, the results aim to provide a first analysis of the use of bed joint reinforcement as strengthening method as well as support the validation of numerical models to be used for further studies.

In order to investigate the efficiency of this strengthening method, the obtained results for the strengthened wall were compared with the ones obtained for previously tested unstrengthened walls [1][2]. The main findings can be summeried as follows:

- The presence of bed joint reinforcements prevent the formation of stepwise cracks at window opening and triggers the formation of horizontal cracks in mortar joints where the reinforcement was not present; for large in-plane displacement the twisted steel bars can trigger an arch mechanism below the window opening. Approaching the end of the test, thanks to the progression of damage the cracks developed also in the bricks at the bottom corners of the wall.

- At the end of the light damage phase, crack width $(-20 \div 25 \%)$ and length $(-25 \div 55 \%)$ reduction were obtained for the strengthened wall.

- For the strengthened wall, a minor increment in terms of base shear $(+15 \%)$, but a significant increment in displacement capacity $(+40 \div 45 \%)$ and in ductility $(+30 \div 40 \%)$ was observed.

- The presence of the twisted steel bars leads to a different evolution of failure mechanisms. For the unstrengthened wall the prevailing mechanisms were rocking of the piers together with the masonry portion above the window opening, and sliding of both the masonry portion above the window opening and the pier P2 with respect the rest of the wall. After the maximum capacity of the wall was reached the steel bars started working, bringing to 
the formation of an arch mechanism in the area underneath the window opening and to toe crushing at the bottom right corner. An important out-of-plane deformation also occurred in the strengthened wall caused by the asymmetric position of the twisted steel bars in the thickness of the wall.

Although the aforementioned outcomes are based on a limited number of tests and further investigations are needed, the reduction of crack width and length and the significant increase in displacement capacity and ductility of wall subjected to in-plane loading suggest that this method can be suitable to strengthen unreinforced masonry buildings in areas with low intensity earthquakes.

Acknowledgements. This research was found by the Rijksdienst voor het Cultureel Erfgoed (RCE) part of the Ministerie van Onderwijs, Cultuur en Wetenschap (OCW), subsides No. MS-2018-189, which is gratefully acknowledged.

\section{REFERENCES}

[1]Korswagen, P., Longo, M. and Meulman, E. Damage sensitivity of Groningen masonry structures - experimental and computational studies. Delft University of Technology. Report no. C31B69WP0-12, version 1, 30 December 2017.

[2]Korswagen, P., Longo, M. and Meulman, E. Damage sensitivity of Groningen masonry structures - experimental and computational studies. Delft University of Technology. Report no. C31B69WP0-13, version 1, 21 December 2018.

[3]Valluzzi M.R., Binda L., Modena C. (2005). Mechanical behaviour of historic masonry structures strengthened by bed joints structural repointing. Construction and Building Materials, 19(2005), 63-73.

[4]NIKER (2010), New integrated knowledge based approaches to the protection of cultural heritage from earthquakeinduced risk.

[5]Ismail N., Petersen R.B., Masia M.J., Ingham J. (2011). Diagonal shear behaviour of unreinforced masonry wallets strengthened using twisted steel bars. Construction and Building Materials, 25(2011), 4386-4393.

[6]Licciardello L., Esposito R. (2019). Experimental study on unreinforced masonry strengthened with bed joint reinforcement. Delft University of Technology. Report no. CM1B07-2, version 1, 28 November 2019.

[7]Kallioras S., Guerrini G., Tomassetti U., Marchesi B., Penna A., Graziotti F., Magenes G. (2017). Experimental seismic performance of a full-scale unreinforced clay-masonry building with flexible timber diaphragms. Engineering Structures, 161(2018), 231-249.

[8]EN 772-1 (2000). Methods of test for masonry units - Part 1: Determination of compressive strength. Nederlands Normalisatie-instituit (NEN).

[9]NEN 6790 (2005). Technical principles for building structures-TGB 1990- Masonry structures - Basic requirements and calculation methods. Nederlands Normalisatie-instituit (NEN).

[10]EN 1015-11 (1999). Method of test for mortar for masonry - Part 11: Determination of flexural strength of hardened mortar. European Committee for Standardisation (CEN).

[11]EN 1052-1 (1998). Method of test masonry - Part 1: Determination of compressive strength. Nederlands Normalisatieinstitute (NEN).

[12]EN 1052-5 (2005). Method of test masonry - Part 5: Determination of bond strength by bond wrench method. Nederlands Normalisatie-institute (NEN).

[13]EN 1052-3 (2002). Method of test masonry - Part 3: Determination of initial shear strength. Nederlands Normalisatieinstitute (NEN).

[14]EN 12190 (2018). Products and systems for the protection and repair of concrete structures - Test methods Determination of compressive strength of repair mortar.

[15]Moreira S., Ramos L.F., Csikai B. (2014). Bond behaviour of twisted stainless steel bars in mortar joints. 9th International Masonry Conference Proceedings, Guimaraes, Portugal.

[16]EN 1766 (2015). Products and systems for the protection and repair of concrete structures -Test methods - Reference concrete for testing. Nederlands Normalisatie-institute (NEN).

[17]Skroumpelou G., Messali F., Esposito R., Rots J.G. (2018). Mechanical characterization of wall tie connection in cavity walls. Proceedings of $10^{\text {th }}$ Australian Masonry Conference, 11-14 February, Sideny Australia.

[18]Mariani, V. Numerical prediction and sensitivity studies of the shaking table test on EUC-BUILD-2. Delft University of Technology, 17 November 2016

[19]Magenes, G., Morandi, P. and Penna, A. (2008). In-plane cyclic tests of calcium silicate masonry walls. Proceedings of $12^{\text {th }}$ International Brick/Block Masonry Conference, 18-20 February, Sydney Australia. 